The University of Maine

DigitalCommons@UMaine

Publications

Senator George J. Mitchell Center for Sustainability

Solutions

$8-2015$

\title{
Are acceptance, support, and the factors that affect them, different? Examining perceptions of U.S. fuel economy standards
}

\author{
Stacia J. Dreyer \\ University of Maine \\ Mario F. Teisl \\ University of Maine, teisl@maine.edu \\ Shannon K. McCoy \\ University of Maine
}

Follow this and additional works at: https://digitalcommons.library.umaine.edu/ mitchellcenter_pubs

\section{Repository Citation}

Dreyer, Stacia J.; Teisl, Mario F.; and McCoy, Shannon K., "Are acceptance, support, and the factors that affect them, different? Examining perceptions of U.S. fuel economy standards" (2015). Publications. 13.

https://digitalcommons.library.umaine.edu/mitchellcenter_pubs/13 
Are acceptance, support, and the factors that affect them, different?

\section{Examining perceptions of U.S. fuel economy standards}

Stacia J. Dreyer ${ }^{a, b},^{*}$, Mario F. Teisl ${ }^{a}$, Shannon K. McCoy ${ }^{b}$

'School of Economics, University of Maine, Orono, ME 04469, USA

b

Department of Psychology, University of Maine, Orono, ME 04469, USA

* Corresponding author at: School of Marine and Environmental Affairs, University of

Washington, Seattle, WA 98105, USA. Tel.: +1 206685 1837. E-mail address:

sdreyer@uw.edu (S.J. Dreyer). 
Understanding the acceptance of and support for transportation policies focused on the environment, such fuel economy standards, is important because of the positive impact policies can have on the environment and overall sustainability goals. This study investigates the acceptance of and support for fuel economy standards through an online survey of Maine residents. Specifically, we assess the Corporate Average Fuel Economy (CAFE) standards, which aim to increase fuel economy of vehicles, while decreasing greenhouses gas emissions and foreign fuel dependence in the United States. We assess how perceptions of the policy and economic views of the market affect acceptance and support. We differentiate acceptance and support on two dimensions, a temporal and attitudinal-behavioral dimension. In doing so, we improve upon traditional measures of these variables and provide evidence that acceptance and support are distinct constructs. We find that perceived fairness, perceived effectiveness, and a subscription to a free-market ideology play a role in acceptance and support. The implications of the findings are discussed in relation to survey methods, policy communications, and an interdisciplinary understanding of environmental policy.

Keywords: Environmental policy, Social justice, Free-market ideology, Surveys, Emissions reduction 
Introduction

Environmental policies correct failures and inefficiencies of the market, and in doing so, address problems related to sustainability: greenhouse gas emissions, pollution, land-use change, loss of biodiversity, etc. Economically speaking, the market does not account for negative externalities, such as greenhouse gas emissions, so environmental policies are created to minimize the externality and bring about balance in the market (Jaffe et al., 2005). From a sustainability perspective, these policies help ensure that there are enough resources for future generations (both human and non-human).Fuel economy standards are one type of environmental policy, which affect the transportation sector. These standards are used to decrease greenhouse gas emissions, and in some cases, foreign dependence on oil, while increasing fuel economy of vehicles.

Fuel economy standards, along with the information labels affixed to vehicles at automobile dealerships, have been shown to be an effective way to reduce the growth rate of energy consumption (Mahlia et al., 2013). Information labels educate consumers about the fuel economy of a vehicle for purchase, along with the annual fuel cost, potential fuel savings, and provide smog, fuel economy, and greenhouse gas ratings. Fuel economy standards can be either mandatory or voluntary, although mandatory standards are more effective for desired rapid changes (Mahlia et al., 2013).

Fuel economy standards are only one type of policy instrument aimed at reducing emissions or increasing fuel economy. Alternative instruments exist such as fuel taxes or 
"feebate" systems which impose fees or provide rebates, depending upon the fuel efficiency of the vehicle (Anderson et al., 2011). In the United States, the Corporate Average Fuel Economy (CAFE) standards represent the existing policy instrument of choice, but they do not include fuel taxes or a "feebate" system. The CAFE standards are discussed in more detail in section 'CAFE standards'.

Standards such as CAFE can also create a market transformation. The fuel economy information labels provide a fair and equitable foundation to compare the energy efficiency of vehicles. In theory, vehicles with the most competitive cost and highest energy ratings will be more desirable than other vehicles, thus increasing consumer demand for these vehicle types and transforming the market (Mahlia et al., 2013). Conversely, the standards also require that automakers supply more energy efficient vehicles, thus shifting the supply side of the market (Anderson et al., 2011) as well as the market of the technologies required to provide those lower emissions (Jaffe et al., 2005).

It is uncertain whether fuel savings exceed the cost of fuel economy standards. This uncertainty, which undoubtedly has policy implications, is partly due to the debate as to whether an "energy paradox" exists in the automobile market (Allcott and Wozny, 2012; Bento et al., 2010; Greene et al., 2013). Broadly speaking, the energy paradox refers to an undervaluation of the future costs of energy compared to current costs. This paradox can be explained by factors related to both market-failure and non-market-failure (Jaffe and Stavins, 1994). It is possible that the energy paradox also impacts perceptions of fuel economy standards (see Greene (2010), Hefland and Wolverton (2009) for a review of consumers' valuation of fuel economy). 
Understanding the acceptance of and support for environmental policies, such as the CAFE standards is important because of the positive impact policies can have on the environment and overall sustainability goals. Without acceptance and support of the public, policies are unlikely to pass through legislative processes, or remain standing when challenged. Understanding what conditions affect acceptance and support of environmental policies can help government officials craft and maintain policies that have public appeal, as well as environmental and socioeconomic benefits. Furthermore, transportation planners would benefit from a better understanding of what is acceptable and/or supported within their local context.

As researchers, fully understanding acceptance and support cannot be accomplished if we do not empirically distinguish the two concepts. As discussed by Dreyer and Walker (2013), these concepts have been used interchangeably within the lit- erature, without operational definitions or standard measurement scales. To address this issue, we have chosen to explore both acceptance and support of environmental policies using the CAFE standards as our policy example. This provides a framework to better understand acceptance of and support for policies and the relationships among variables of interest such as perceived fairness, effectiveness, and a subscription to a free-market ideology.

We begin with an overview of the literature on acceptance and support of environmental policies and renewable energy technologies and then describe the CAFE standards in more detail. The review leads into a description of the survey methods and results. We conclude with a discussion of our results and the implications for 
environmental policies.

Acceptability, acceptance, and support

In general, support and acceptance have not been operationally defined within the environmental or transportation pol- icy literature. Recently, there has been a call to operationally define these terms (Dreyer and Walker, 2013; Batel et al., 2013). Operationally defining, and thus distinguishing these terms from one another, is important for not only theoretical reasons, but also empirical and applied policy reasons. The interchangeable use of these terms has led to a lack of specificity in existing empirical measures. As a result, it is possible that studies have measured acceptance instead of support or support instead of acceptance. Problems may arise from this mix-up, especially when policy decisions are based on potentially erroneous data. In addition, depending upon the policy context, it may be important to stress one concept over the other. Without understanding the differences between acceptance and support, one could not target support over acceptance, or vice versa, when designing policy communications.

When speaking about favorable or unfavorable evaluations/attitudes of an environmental policy, some researchers prefer the term "support" and use it consistently throughout their writing (Dietz et al., 2007; Leiserowitz et al., 2012), while others use the term "acceptance" or "acceptability" interchangeably with support (Gross, 2007; Schuitema et al., 2010; Steg et al., 2005, 2006; Swim et al., 2011; Wegener and Kelly, 2008). In addition, Stern et al. (1999) identify and describe three dimensions of support for environmentalism: citizen action, policy support and 
acceptance, and personal sphere behavior. However, within the second dimension, policy support and acceptance, no description of the similarities and differences between policy support and policy acceptance or policy acceptability is offered. These examples highlight the lack of common definitions and understanding of acceptance and support.

It has been established that acceptance of a policy differs from acceptability of a policy. Acceptability is a favorable or unfavorable evaluation of a policy before implementation, whereas acceptance is the evaluation after implementation (Schade and Schlag, 2003; Schuitema et al., 2010). Schade and Schlag include a behavioral component in their definition of acceptance, whereas other researchers see the behavioral component existing within support (Dreyer and Walker, 2013).

Recently, a few scholars have attempted to operationalize acceptance and/or support for renewable energy technologies (RET) and the associated RET infrastructure. Rau et al. (2012) examined the determinants of RET acceptance and the relationship of those determinants with public participation such as opinion polls and round tables. Rau and colleagues argue that acceptance can be conceptualized on a spectrum defined by two facets: appraisal (positive to negative) and action (passive to active). A positive appraisal is a necessary precondition to acceptance and a positive appraisal with active action results in support or commitment to a various RET projects, which is also described as active acceptance. Furthermore, Rau et al. (2012) differentiate between general acceptance of renewable energies, acceptance of various renewable energies, and active acceptance. General acceptance and acceptance of various renewable energies include a positive appraisal, absent of active 
action, whereas active acceptance includes positive appraisal and active action.

Batel et al. (2013) offer a critical discussion on acceptance and support of RET, extending the work of Rau et al. (2012). They state that acceptance appears to "involve a reaction to something-external-and one which is mainly characterised by passivity and non-decision" whereas support "seems more clearly to be actionoriented,... to imply agency for and engagement with something" (2013, p. 2). Furthermore, they argue that acceptance and support can be viewed in light of the distinction between the terms risk and danger. The two terms have been used interchangeably within the literature although they are conceptually different. Risk is internally-driven and the result of a decision (or agency) while danger is not the result of a decision and is externally-driven (Batel et al., 2013). Dreyer and Walker (2013) make a similar argument, with the two phrases "willingness to pay" and "willingness to accept" which have been used interchangeably within the economics literature.

Batel et al. (2013) further argue that if active engagement and public support are goals of RET, then it is important that we not only study acceptance but also support for RET. Through a survey of national samples in Norway and the United Kingdom (UK), Batel et al. (2013) assessed responses towards power lines, attempting to distinguish acceptance from support. They measured acceptance and support at a general level ("In general...") as well as local level ("near your community...") and found that ratings of acceptance and support are consistently positive, but ratings of support are consistently and significantly lower than acceptance both locally and generally in Norway and the UK. This could be due to the higher behavioral cost that support has compared to acceptance. Thus, it might be the case that support for a RET or an environmental policy may be 
overestimated, if acceptance is really being measured. Or, conversely, acceptance of a RET or policy may be under- estimated if support is really being measured.

These findings are consistent with Dreyer and Walker (2013), who found higher levels of acceptance versus support for the Australian carbon policy. In addition, they found that both perceived fairness and effectiveness predicted acceptance and support. However, there were two additional determinants for support: lower levels of free-market ideology (FMI) and the interaction between FMI and effectiveness. Conceptually, they argue that support and acceptance differ on two dimensions, an attitudinal-behavioral dimension, as well as a temporal dimension (Dreyer and Walker, 2013). By extension, acceptability and acceptance both include a passive attitude structure, but differ on the temporal dimension because acceptability relates to positive attitudes towards a policy before the policy is implemented, whereas acceptance relates to positive attitudes after the policy is implemented. Support includes this same attitude structure, but also embodies a more active behavioral dimension and spans the before implementation/after implementation policy divide (Dreyer and Walker, 2013). For example, if a policy is proposed, one may support its future implementation through political actions such as calling a representative to indicate their support, or gaining signatures on a petition. One may support its immediate implementation through voting. Lastly, one may support its continued existence through a number of actions or intentions to act if the policy was at risk of being overturned (Dreyer and Walker, 2013).

This study attempts to create a better, more accurate measurement of acceptance and support, based on the small amount of current literature that distinguishes the two 
concepts, as discussed within this section. This literature uses the word "accept" to denote acceptance or acceptability, as well as looking at how much one "favors," "prefers," or "agrees." Thus, these terms were used within the multiple statements to assess acceptance of the fuel economy standards. Fewer examples exist for assessing support. Most use "support" as the verb of choice in the statement (Batel et al., 2013; Dreyer and Walker, 2013) while others include "support or oppose" (Leiserowitz et al., 2012). Other studies confuse acceptance and acceptability with support and use verbs indicating a positive or negative evaluation, but fail to incorporate a behavioral component. To better answer our question of "what is support?" it was helpful to identify characteristics of a "supporter" by drawing from Stern et al. (1999) definition of a supporter of the environmental movement: "supporters are those who are sympathetic to the movement and who are willing to take some action and bear some of the costs in order to support the movement" (p. 82). Deconstructing this definition, there is a positively aligned evaluation (sympathy) of the attitude object (the movement), and a behavioral component (taking action and bearing costs). With this in mind, our support statements were created using similar terminology, in addition to asking participants how likely they would be to take specific actions regarding the fuel economy standards, which also reflected a positive evaluation of the attitude object.

Perceived Fairness (FAIR) and Effectiveness (EFF)

Concepts of social justice, specifically those of distributive and procedural justice, need to be considered when creating (Bubna-Litic and Chalifour, 2012; Gross, 2007) and evaluating environmental policies (Dreyer and Walker, 2013). Distributive justice refers to outcomes one receives from the policy and how those compare to the 
outcomes others receive.

Procedural justice refers to the processes that were used to inform the outcomes (Tyler et al., 1997; see Thibaut and Walker, 1975 for seminal work). Fairness of a policy is a main concern for many individuals, and as such, perceived fairness is positively related to policy acceptance (Dreyer and Walker, 2013; Skitka et al., 2003; Tyler, 2000; Visschers and Siegrist, 2012) and support (Dreyer and Walker, 2013). In accordance with Dreyer and Walker (2013), our study investigates aspects of fairness within distributive justice, as opposed to procedural justice due to survey constraints.

Similar to perceived fairness, perceived effectiveness is positively related to policy acceptability (Eriksson et al., 2008; Gärling and Schuitema, 2007; Steg et al., 2006) and policy acceptance and support (Dreyer and Walker, 2013). It makes sense that people want a policy to be effective - to create the changes the policy sets out to create. Given the past literature, we hypothesize that policy acceptance will be positively related to perceived fairness and effectiveness and similarly that policy support will be positively related to perceived fairness and effectiveness. Based on prior work, the relationship between effectiveness and support may be more complex than between effectiveness and acceptance, specifically how effectiveness interacts with free-market ideology (Dreyer and Walker, 2013). Therefore, we test moderation effects in our analyses.

Free-market ideology (FMI)

FMI is the belief that markets should be allowed to exist unrestrained by 
government regulations. FMI posits that the market will resolve any problems which occur through supply and demand dynamics (Heath and Gifford, 2006). Smith (1904) argues that an "invisible hand" is the control mechanism for the market and this prevents market failure and therefore the need for government policy intervention. If the market can resolve any issues independent of government policy, then individuals do not need to concern themselves with the environmental costs of the market (Dreyer and Walker, 2013). Subscription to a free-market ideology is associated with both the rejection of climate science (Lewandowsky et al., 2013) and a belief that global warming is naturally caused (Heath and Gifford, 2006). In addition, a subscription to free-market ideology was found to be negatively related to acceptance and support of a carbon policy (Dreyer and Walker, 2013).

As the fuel economy standards are a government regulation that, in part, seeks to reduce greenhouse gas emissions, we hypothesize a negative relationship between FMI and acceptance and support of the fuel economy standards. However, if the policy is perceived to be highly effective, the direct relationship between FMI and support may be weakened (Dreyer and Walker, 2013).

CAFE standards

In the U.S., the CAFE standards were born out of the 1973 oil crisis and were formally established through the Energy Policy and Conservation Act of 1975. This act mandated an increase in fuel economy of passenger cars and light-duty trucks (NRC, 2002). Many revisions have been made since the inception of these standards, most recently in 2012, which finalized the standards for model years 2017-2025. In addition, 
serving under the Clean Air Act, the Environmental Protection Agency is now working in partnership with the National Highway Traffic Safety Administration for these standards, representing a "harmonized and consistent National Program" (Department of Transportation (DOT), 2012, p. 62,624).

Much literature exists regarding the economic pros and cons of these standards in terms of efficiency, effectiveness, impacts, (NRC, 2002; Greene and Hopson, 2003), incentives, penalties (Mahlia et al., 2013), welfare effects (Parry et al., 2007), the energy paradox (McConnell, 2013) and in general, addressing the negative externality of greenhouse gases that result from vehicle use (Jaffe et al., 2005; Parry et al., 2007; Santos et al., 2010). These studies are needed because of their policy implications. However, this research is based heavily within the economics literature and there appears to be a gap where other human dimensions of these standards are not addressed.

It is important that alongside these economic analyses of the CAFE standards we also address how individuals perceive the policy and the determinants of acceptance of and support for these standards. Acceptance and support of certain policies dealing with negative externalities like greenhouse gases have been studied in the past. However, analyses of the determinants of acceptance and support of the CAFE standards specifically, are largely absent in the peer-reviewed literature. Over the last few decades, polls have been conducted to measure public opinions of these standards. The Consumer Federation of America (CFA) has been conducting yearly, and sometime bi-yearly, polls since the mid-2000s and continuously have found high levels of support, even across partisan lines (CFA, 2014). Greene (1998) summarizes the opinions on the standards from the late 1980s through the 1990s and also shows overall high levels of favorability or 
support. These polls indicate that the CAFE standards, or more generally fuel efficiency standards, are widely accepted and supported by the American public. However these surveys normally do not assess predictors of the opinions, nor do they measure the constructs based on multiple items. Furthermore, they do not empirically distinguish between acceptance and support, making it difficult to compare across surveys. With these considerations in mind, we investigate the acceptance and support of the CAFE standards in relation to its perceived fairness and effectiveness, and whether acceptance and support are related to an individual's subscription to free-market ideology.

\section{Material and Methods}

The following hypotheses regarding the CAFE standards were tested with an online survey with residents living in Maine, USA.

Hypotheses:

Average acceptance (ACC) will be significantly higher than support (SUP) for the CAFE standards.

(2)

ACC will be positively related to FAIR and EFF and negatively related to FMI. SUP will be positively related to FAIR and EFF and negatively related to FMI.

(4) Main effects for FAIR, EFF and FMI will be found in both ACC and SUP.

To test $\mathrm{H} 1$, we used paired-samples $t$-tests of means to determine whether ACC is larger than SUP.

To test $\mathrm{H} 2, \mathrm{H} 3$ and $\mathrm{H} 4$, we performed two independent hierarchical (sequential) 
multiple regressions using ordinary least squares estimation techniques with the level of ACC or SUP as the dependent variable and EFF, FAIR, and FMI as independent variables (see Table 1 for items associated with each variable).

In step 1 of the hierarchical regressions, the centered predictor variables of perceived EFF, FAIR and FMI are entered:

ACC or SUP $=\alpha+\beta_{1}$ EFF $+\beta_{2}$ FAIR $+\beta_{3}$ FMI $+e$

In step 2, three two-way interactions among the independent variables are entered (see Table 4).

ACC or SUP

$=\mathrm{a}+\beta_{1} \mathrm{EFF}+\beta_{2} \mathrm{FAIR}+\beta_{3} \mathrm{FMI}+\beta_{4} \mathrm{FAIR} * \mathrm{EFF}+\beta_{5} \mathrm{FAIR} * \mathrm{FMI}+\beta_{6} \mathrm{EFF} * \mathrm{FMI}+\mathrm{e}$

To test $\mathrm{H} 2$ (ACC) and $\mathrm{H} 3$ (SUP) then $\beta_{1}>0, \beta_{2}>0$ and $\beta_{3}<0$; to test $\mathrm{H} 4 \beta_{1}, \beta_{2}$, and $\beta_{3}$ are always not equal to zero.

Participants

Participants were recruited from an email database managed by InfoUSA ${ }^{\circledast}$ and those participants who were living in Maine, USA were randomly selected to take part in this survey. Participants received an invitation letter to participate in the survey via email. At the bottom of the invitation was a hyperlink, which they were instructed to click on if they wished to participate. The link connected participants to the survey on Qualtrics ${ }^{\circledR}$, a web-based survey tool. After giving consent to participate, participants began the survey, 
which took approximately 10 min to complete. Included was an incentive to be entered into a prize drawing for a $\$ 50$ L.L. Bean ${ }^{\circledR}$ gift certificate.

Of the 23,594 email invitations that were sent, 20,458 were delivered into email inboxes. Of these, only a total of 1,075 invitations were opened (known contacts). 267 individuals clicked the hyperlink to be brought to the online survey, and of those, 206 began the survey. In all, we collected useable data from 165 participants, (101 female, 63 male, 1 no gender response) which we use in the following analyses. This results in a $.70 \%$ response rate, a $5.2 \%$ contact rate, and a $12.7 \%$ cooperation rate. The survey was open for approximately 2 weeks, with an email reminder sent at the beginning of the second week.

The mean age of participants was 54.7 years old, $(S D=14.04)$, with a median income of $\$ 70,000-\$ 79,000$, and a median education level of a college degree. On average, participants were older, more highly educated, and earned higher incomes as compared to the population of Maine. See Table 2. Although our respondents are not representative of the state population as a whole, our purpose here is not to make statements about the population but test to see if acceptance and support are separate constructs and, if they are, what are the factors that influence them.

Measures

Descriptions of each measure according to questionnaire section are listed below. Prior to the implementation of this survey, expert review was solicited to assess question clarity for each measure and possible response errors (Dillman, 2007). 
Section 1 - Fuel economy standards

This section assessed acceptance based on questions created specifically for the fuel economy standards. To ensure all participants had a basic knowledge of the standards, a brief introductory summary was presented with facts taken from the National Highway Traffic Safety Administration website. This statement also showed an image of a typical information label affixed to all new vehicles for purchase. All questions in this section were presented in random order, following the summary and knowledge questions, to control for order effects.

Knowledge. Participants rated their knowledge of the fuel economy standards with two statements using 5-point Likert items: "Before reading the above information, did you know the fuel economy standards existed" and "Before today, had you ever seen the fuel economy labels for new vehicles?"

Acceptance. Participants rated their levels of acceptance of the fuel economy standards with 4 statements using 5-point Likert items. These statements were specific to the policy. Response categories were relative to the question wording, for example, "How acceptable do you find the fuel economy standards" ranged from "completely unacceptable" to "completely acceptable." Other questions in this category were: "To what extent are you in favor for or against the fuel economy standards," "To what extent do you agree or disagree with the fuel economy standards," and "Do you prefer having the fuel economy standards in place, as opposed to no fuel 
economy standards?" Acceptance was measured as the average of the 4 questions ( $\alpha$ $=.91)$.

Support. Participants rated their levels of support of the fuel economy standards through seven statements using 5-point Likert items. As with the acceptance questions, response categories reflected question wording. Questions included were: "How supportive are you of the fuel economy standards," "How willing are you to bear some of the costs resulting from the fuel economy standards," "How willing are you to take action to voice a positive opinion about the fuel economy standards, such as writing a letter or calling a representative" as well as others. These questions were averaged to create the sup- port score $(\alpha=.84)$.

Perceived fairness. Participants indicated how fair they perceived the standards to be towards manufacturers, consumers, and individuals with four statements using 5-point Likert items: "How fair do you think it is that manufacturers of vehicles must increase the fuel economy of their fleets, as mandated by the fuel economy standards," "How fair do you think it is that manufacturers of vehicles need to decrease the greenhouse gas emissions emitted by their vehicles...," "How fair do you think it is that consumers will have to pay more for a new vehicle, as a result of technologies needed to achieve the fuel economy standards," "How fair do you think it is that you will have to pay more for a new vehicle ..." These questions were averaged to create the fairness score $(a=.83)$.

Perceived effectiveness. Participants indicated perceived effectiveness of the fuel economy standards with two statements using 5-point Likert items: "How effective do you think the fuel economy standards will be to help increase vehicle fuel economy in the 
US" and "How effective do you think the fuel economy standards will be to help lower greenhouse gas emissions in the US?" These questions were averaged to create an effectiveness score $(r=.56)$.

Section 2 - Free-market ideology

This section included Heath and Gifford's (2006) free-market ideology (FMI) scale whereby statements were measured with 5-point Likert items ranging from "Strongly Disagree" to "Strongly Agree." The FMI scale included statements such as: "An economic system based on free-markets unrestrained by government interference automatically works best to meet human needs" and "The preservation of the free-market system is more important than localized environmental concerns" as well as four other statements (see Appendix A). All statements in this section appeared in random order to control for order effects. $(\alpha=.83)$. Responses were recoded so that a higher score aligned with endorsement of a free-market ideology. One statement was omitted from further analysis from this scale in accordance with previous literature: "I support the free market system but not at the expense of environmental quality" (Lewandowsky et al., 2013; Dreyer and Walker, 2013).

Section 3 - Demographics

We assessed gender, income, age, education, ethnicity, and race. Gender was coded: male (0), female (1). We included 12 response categories for income, varying from “less than $\$ 10,000 "$ coded as a 1 , to “more than $\$ 250,000 "$ coded as 12 . Age responses 
were coded so that higher values represented increased age. We assessed education with 5 response categories ranging from "0-11" years coded as 1, to "Postgraduate, Master's, Doctorate, Law, or other" coded as 5. The survey included ethnicity and race categories as used by the U.S. Census (United States Census Bureau, 2014) however, lack of variability precluded us using these categories in the analysis.

\section{$\underline{\text { Results }}$}

Basic descriptive statistics analyses were performed first. Paired sample $t$ tests were used to investigate significant differences between acceptance and support ratings. Finally, multiple regressions based on ordinary least square estimators were used to assess predictors of acceptance and support.

Descriptive analyses

Most respondents report some knowledge of the CAFE standards; $73.3 \%$ indicate that they knew the standards existed, or that they knew they existed and were knowledgeable about the standards. In addition, $78.2 \%$ of participants indicated that they had seen the labels on vehicles for purchase. These labels inform consumers about the fuel economy of a vehicle for purchase, along with the annual fuel cost, potential fuel savings, smog rating, and the fuel economy and greenhouse gas rating.

A large majority of the participants accepted $(86.1 \%)$ or supported $(66.1 \%)$ the standards (Table 3). No participant indicated support without acceptance; however, some participants indicated acceptance without support. Paired-samples $t$ tests showed 
significant mean differences between acceptance and support. As hypothesized, participants were more likely to indicate acceptance of the policy compared to support for the policy $(M=4.04, M=3.12$ respectively, $t(161)=17.48, p<.001)$.

Due to violations of ANOVA assumptions regarding unequal cell size, we were limited in our analysis of the differences between those who accept and support, accept but do not support, or do not accept and do not support. However, a frequency analysis shows differences in the percentage of individuals within those groups who intend to purchase a vehicle in the next 5 or 10 years, as well as believing that climate change is a problem that deserves attention and is human caused (Table 4).

Acceptance was significantly and positively correlated with support, perceived fairness, and effectiveness, and was negatively and significantly correlated with a subscription to a free-market ideology (Table 5). This pattern held true for support.

Acceptance and fairness are highly correlated $(r=.81, p<.001)$, but we retain fairness in the following regression model based on the importance of the variable within the literature.

Regression analysis

After step 1, the predictor variables for acceptance accounted for three-fourths of the variance, $F(3,157)=160.23, p<.001$, adjusted $R^{2}=.75$. The addition of the interaction variables at step 2 resulted in a small but statistically significant change in $R^{2}$, 
$\Delta R^{2}=.02, p=.01$, and none of the interactions entered at Step 2 were significant (Adjusted $\left.R^{2}=.76, F(6,154)=86.39, p<.001\right)$. Significant main effects were found for perceived fairness, effectiveness, and FMI (Table 6).

After step 1, the predictor variables for support accounted for almost two-thirds of the variance, adjusted $R^{2}=.62, F(3,156)=89.10, p<.001$. The addition of the interactions at step 2 did not result in a significant and meaningful change in $R^{2}, \Delta R^{2}=$ $.01, p=.39$, adjusted $R^{2}=.62, F(6,153)=89.10, p<.001$. Significant main effects were found for fairness and free-market ideology. Due to shared variance between fairness and effectiveness, effectiveness was not a significant predictor when fairness was in the model.

\section{Discussion}

The results support the hypothesis that levels of acceptance are significantly higher than support - i.e., acceptance is different than support. As the opportunity costs of support are higher than that of acceptance (support requires a behavioral component), it makes sense that stated levels of acceptance are higher than support. These results give evidence to the distinction between the two concepts and corroborate the findings of Batel et al. (2013) and Dreyer and Walker (2013). If acceptance and support were the same concept, we would find no significant differences between them.

The hypotheses regarding the regression analyses were only partially confirmed. 
For acceptance, it appears that higher levels of fairness and effectiveness, and lower levels of free-market ideology predict acceptance. This relationship is also true for support, but it is more nuanced. In regards to support, perceived fairness appears to be more important to the story. Although perceived effectiveness is related to support (as well as free-market ideology), the relationship between perceived fairness and support is stronger. As fairness and effectiveness share much of the same variance, the relationship between effectiveness and support is no longer significant when fairness is in the model.

One implication could be that to increase policy support, campaigns and interventions should stress aspects of fairness, or social justice. Consideration could be given to make sure that procedural and distributive justice concerns are acknowledged and acted upon. However, if the interest is to increase policy acceptance, then addressing the effectiveness of a policy as well as justice aspects of the policy is important.

Regardless of the predictors of policy acceptance and policy support and how these interact with each other psychometrically or econometrically, we find that both fairness and effectiveness play a role in policy support and acceptance. Furthermore, belief in a free-market ideology appears to reduce policy acceptance and support. It might, therefore, be helpful to develop education alongside policy communications that addresses how negative externalities develop within free-markets, and how government intervention via policy is needed to rectify these externalities.

This study improves upon traditional measures of acceptance and support. The results highlight the importance for researchers crafting surveys to assess acceptance of and support for environmental policies to realize the distinctness of these 
concepts, and how they should be measured accordingly. Theories of environmentally significant behavior, attitude change, and political action will benefit from having the terms of acceptance and support defined. As theories are used to create models with predictive power, it is important that theories are well defined and correct on a conceptual level.

This research helps form a clearer picture of the acceptance of and support for environmental policies, specifically the fuel economy standards. The empirical evidence supports the two-dimensional differentiation of Dreyer and Walker (2013). The evidence also supports the argument of Batel et al. (2013) who also conclude that acceptance and support are distinct concepts, sharing similarities. In general, ratings of acceptance are higher than that of support. Additionally, perceived effectiveness, perceived fairness, and FMI account for a large proportion of the variance in both acceptance and support of this environmental policy.

For policy makers, the implications concern communications and the emphasis on either support or acceptance. At times, it may be more important to stress one over the other, depending upon the policy context. Communication strategies utilizing normative theory whereby injunctive norms are paired with descriptive norms to promote behavioral change (Cialdini et al., 2006; Kallgren et al., 2000) could be an effective strategy when stressing one concept over the other. For example, if one were trying to increase support, they could focus on communicating the already high levels of acceptance, paired with specific actions one could take to support the policy. 
be inferred from Batel et al.'s (2013) reported results, although not stated as such. By comparing levels of acceptance with levels of support at the individual level, we found that no single participant indicated that they supported but did not accept the standards. We instead found, individuals who did not accept and did not support, who accepted but did not support, and who accepted and supported. These groups differed in their likelihood to purchase or lease a vehicle in the next 5 or 10 years, as well as their belief that climate change is human caused and a problem that deserves attention (with the exception of those who accept and support and those who do not accept and do not support for purchasing/leasing a vehicle).

Our study was limited in few ways. It is limited in generalizability to Maine residents because of our small sample size and because our participants were older, more highly educated, and earned higher incomes as compared to the population of Maine. While we sampled randomly from our sample frame, this does not ensure representativeness. Our response rate was low, although the amount of "click-ins," the number of people who click the survey link from their email invite, was well within the average of other surveys conducted by InfoUSA. ${ }^{\circledR}$ In addition, our results may be susceptible to non-response bias as individuals who did not answer our survey questions may be different from those who did. Funding limitations impacted our ability to follow up with non-respondents to assess bias. Future research would address these issues with a larger sample size and assess for non-response bias. Nonetheless, the results do support the theoretical contribution of this paper, providing empirical evidence for the conceptual distinction between acceptance and support. 
that assess not only perceptions of the increased cost of higher fuel economy, but also that of perceived fuel savings. This would allow for a more balanced measurement of perceptions of the standards. Implications for this study is that our measure for fairness of the standards may be negatively biased, resulting in lower perceived fairness ratings because we inquired about costs but not savings within our fairness questions.

Future research on acceptance and support could compare different transportation and environmental policies with similar goals but different means of achieving those goals. This research could investigate how the similarities and differences of the policies impact levels of acceptance and support, as well as whether any differences at the individual or group level exist within acceptance or support across policies.

Our findings offer methodological, theoretical, and empirical contributions to the literature on the acceptance of and sup- port for fuel economy standards. Literature exists regarding the economic pros and cons of the CAFE standards. However, the acceptance and support of the standards at an individual level, and the factors that impact them, has not been well established. This article provides a base for that knowledge, and adds to a more interdisciplinary understanding of this policy while providing operational definitions and methodology that may prove useful to researchers across many disciplines. 
Acknowledgements

We gratefully acknowledge funding support by: the Maine Sustainability Solutions Initiative (supported by National Science Foundation award: EPS-0904155 and Maine EPSCoR at the University of Maine), and the Maine Agricultural and Forest Experiment Station. We also thank Laura Lindenfeld, Linda Silka, Sarah Newcomb, and Ryan Pickering for their helpful comments on an earlier dissertation version of this manuscript, as well as three anonymous reviewers for their comments on this manuscript. 


\section{Figures}

Table 1

Items associated with each variable.

\begin{tabular}{|c|c|c|}
\hline Variable & Variable label & Items \\
\hline ACC & Acceptance & $\begin{array}{l}\text { How acceptable do you find the fuel economy standards } \\
\text { To what extent are you in favor for or against the fuel economy standards } \\
\text { To what extent do you agree or disagree with the fuel economy standards } \\
\text { Do you prefer having the fuel economy standards in place, as opposed to no fuel economy standards }\end{array}$ \\
\hline SUP $^{2}$ & Support & $\begin{array}{l}\text { How supportive are you of the fuel economy standards } \\
\text { How willing are you to bear some of the costs resulting from the fuel economy standards } \\
\text { How willing are you to take action to voice a positive opinion about the fuel economy standards, such as writing a } \\
\text { letter or calling a representative } \\
\text { In regards to the fuel economy standards, how likely are you to: } \\
\text { - Voice a positive opinion to a family member } \\
\text { - Express a positive opinion on social media, such as Facebook } \\
\text { - Voice a positive opinion to a co-worker } \\
\text { - Write a positive opinion letter to a newspaper }\end{array}$ \\
\hline FAIR & $\begin{array}{l}\text { Perceived } \\
\text { fairness }\end{array}$ & $\begin{array}{l}\text { How fair do you think it is that manufacturers of vehicles need to decrease the greenhouse gas emissions emitted by } \\
\text { their vehicles as mandated by the CAFE standards } \\
\text { How fair do you think it is that consumers will have to pay more for a new vehicle, as a result of technologies needed } \\
\text { to achieve the fuel economy standards }\end{array}$ \\
\hline EFF & $\begin{array}{l}\text { Perceived } \\
\text { effectiveness }\end{array}$ & $\begin{array}{l}\text { How effective do you think the fuel economy standards will be to help increase vehicle fuel economy in the US } \\
\text { How effective do you think the fuel economy standards will be to help lower greenhouse gas emissions in the US }\end{array}$ \\
\hline FMI & $\begin{array}{l}\text { Free-market } \\
\text { ideology }\end{array}$ & $\begin{array}{l}\text { An economic system based on free-markets unrestrained by government interference automatically works best to } \\
\text { meet human needs } \\
\text { The preservation of the free-market system is more important than localized environmental concerns } \\
\text { The free-market system may be efficient for resource allocation, but it is limited in its capacity to promote social } \\
\text { justice } \\
\text { Free and unregulated markets pose important threats to sustainable development } \\
\text { The free-market system is likely to promote unsustainable consumption }\end{array}$ \\
\hline
\end{tabular}

${ }^{2}$ Negatively framed behavioral items were also included to measure opposition, but they are not included within these analyses. 
Table 2

Descriptive statistics for participanłs compared to Maine population.

\begin{tabular}{llll}
\hline & Mean age & Median income & Median education level \\
\hline Maine sample & $54.7(14.04)$ & $\$ 70,000-\$ 79,000$ \\
Maine population ${ }^{2}$ & 42.7 (median) & $\$ 48,219$ & College degree \\
\hline
\end{tabular}

a US Census Bureau (2014). 
Table 3

Frequency of participants accepting and/or supporting the CAFE standards.

\begin{tabular}{llll}
\hline & Not Support & Support & Total \\
\hline Not accept & 16 & 0 & $16(13.9 \%)$ \\
Accept & 23 & 76 & $99(86.1 \%)$ \\
Total & $39(33.9 \%)$ & $76(66.1 \%)$ & $115(100 \%)$ \\
\hline
\end{tabular}

Note: With an index score ranging from 1 to 5, participants scoring between 1 and 2.74 were considered "Not accepting/supporting" and those who scored 3.26-5 were considered as "Accepting/supporting." Participants whose index scores indicated that they neither accepted nor did not accept the policy 2.75-3.25 were not considered in this analysis, following Batel et al. (2013). 
Table 4

Frequency analysis of key statements across 3 groups of Accept/Support.

\begin{tabular}{llll}
\hline & Accept and Support & Accept but do not Support & Do not Accept and do not Support \\
\hline Likely to purchase/lease a car within 5 years & $61.8 \%$ & $43.5 \%$ & $62.5 \%$ \\
Likely to purchase/lease a car within 10 years & $75.3 \%$ & $47.8 \%$ & $75.0 \%$ \\
Believes climate change is a problem that deserves attention & $93.4 \%$ & $60.9 \%$ & $12.5 \%$ \\
Believes climate change is human caused & $89.5 \%$ & $65.2 \%$ & $6.3 \%$ \\
Total & 76 & 23 & 16 \\
\hline
\end{tabular}


Table 5

Correlations between variables and descriptive statistics.

\begin{tabular}{|c|c|c|c|c|c|c|c|c|c|}
\hline & \multicolumn{2}{|c|}{ Dependent variables } & \multicolumn{7}{|c|}{ Explanatory variables } \\
\hline & Acceptance & Support & Fairness & Effective & FMI & Gender & Age & Education & Income \\
\hline Acceptance & 1.00 & - & - & - & - & - & - & - & - \\
\hline Support & $.76^{* *}$ & 1.00 & - & - & - & - & - & - & - \\
\hline Fairness & $.81^{* *}$ & $.74^{* *}$ & 1.00 & - & - & - & - & - & - \\
\hline Effective & $.75^{* *}$ & $60^{*-}$ & $.71^{*-}$ & 1.00 & - & - & - & - & - \\
\hline FMI & $-.69^{* *}$ & $-.68^{* *}$ & $-.61^{* *}$ & $-.57^{* *}$ & 1.00 & - & - & - & - \\
\hline Gender & .04 & .05 & .01 & .01 & -.06 & 1.00 & - & - & - \\
\hline Age & .11 & .06 & .13 & .09 & -.12 & -.42 & 1.00 & - & - \\
\hline Education & .04 & .11 & .11 & .04 & -.03 & -.04 & .07 & 1.00 & - \\
\hline Income & .04 & .05 & .05 & .10 & -.02 & $-.27^{* *}$ & $30^{*}$ & $.42^{* *}$ & 1.00 \\
\hline$M(S D)$ & $4.04(.99)$ & $3.12(.90)$ & 3.68 (1.08) & $3.70(.89)$ & $2.61(.84)$ & $\mathrm{N} / \mathrm{A}$ & $53.5(13.97)$ & $\mathrm{N} / \mathrm{A}$ & $\mathrm{N} / \mathrm{A}$ \\
\hline$n$ & 164 & 163 & 164 & 164 & 164 & 164 & 164 & 165 & 156 \\
\hline
\end{tabular}

Note: Above values are Pearson Correlations between variables with the exception of the last two rows, which report descriptive statistics as listed. Median education level is "college graduate" and median income is between $\$ 70,000$ and $\$ 79,000$.

" $p<.05$.

p $<.01$. 
Table 6

Hierarchical multiple regression models for policy acceptance and support.

\begin{tabular}{|c|c|c|c|c|c|c|c|c|}
\hline \multirow{2}{*}{$\begin{array}{l}\text { Dependent } \\
\text { variables }\end{array}$} & \multicolumn{8}{|c|}{ Explanatory variables } \\
\hline & Step & & Fairness & Effectiveness & $\begin{array}{l}\text { Free-market } \\
\text { Ideology (FMI) }\end{array}$ & Fairness * Effectiveness & Fairness * FMI & Effectiveness * FMI \\
\hline \multirow[t]{6}{*}{ Acceptance } & 1 & $b(S E)$ & $.43(.06)^{* *}$ & $35(.07)^{* *}$ & $-.25(.06)^{\cdots}$ & - & - & - \\
\hline & & $\mathrm{Cl}$ & {$[.32, .54]$} & {$[.22, .48]$} & {$[-.37,-.13]$} & - & - & - \\
\hline & & $s r^{2}$ & .53 & .40 & -.31 & & & \\
\hline & 2 & & $.42(.06)^{* *}$ & $.26(.07)^{* *}$ & $-.24(.06)^{\cdots *}$ & $-.07(.04)$ & $.08(.07)$ & $-.01(.08)$ \\
\hline & & & {$[.32, .53]$} & {$[.12, .41]$} & {$[-.36,-.11]$} & {$[-.16, .02]$} & {$[-.06, .22]$} & {$[-.17, .15]$} \\
\hline & & & .53 & .28 & -.29 & -.13 & .09 & -.01 \\
\hline \multirow[t]{6}{*}{ Support } & 1 & $b(S E)$ & $.39(.06)^{* .}$ & $.08(.07)$ & $-.38(.07)^{\cdots *}$ & - & - & - \\
\hline & & & {$[.27, .51]$} & {$[-.06, .23]$} & {$[-.51,-.24]$} & - & - & - \\
\hline & & & .46 & .08 & -.41 & & & \\
\hline & 2 & & $.40(.06)^{* \cdots}$ & $.12(.08)$ & $-.34(.07)^{\cdots *}$ & $.07(.05)$ & $.08(.08)$ & $.01(.09)$ \\
\hline & & $\mathrm{Cl}$ & {$[.28, .52]$} & {$[-.05, .28]$} & {$[-.48,-.20]$} & {$[-.03, .17]$} & {$[-.08, .23]$} & {$[-1.73, .19]$} \\
\hline & & $s r^{2}$ & .47 & .11 & -.36 & .11 & .08 & .01 \\
\hline
\end{tabular}

Note: Cell entries for Acceptance and Support in line 1, are unstandardized ordinary least squares regression coefficients (b). Standard errors (SE) are in parentheses following. The second line is the $95 \%$ confidence interval $[\mathrm{Cl}]$ for $b$, with squared partial cor relation coefficient following. This is repeated for Step 1 and Step 2. Explanatory variables centered at the mean to reduce multicollinearity issues in the interaction terms.

- $p \leqslant .05$.

$\cdots p<.01$.

$p<.001$. 


\section{References}

Allcott, H., Wozny, N., 2012. Gasoline Prices, Fuel Economy, and the Energy Paradox. NBER Working Paper No. 18583. http://dx.doi.org/10.3386/w18583.

Anderson, S.T., Parry, I.W.H., Sallee, J.M., Fischer, C., 2011. Automobile fuel economy standards: impacts, efficiency, and alternatives. Rev. Environ. Econ.

Policy 5 (1), 89-108. http://dx.doi.org/10.1093/reep/req021.

Batel, S., Devine-Wright, P., Tangeland, T., 2013. Social acceptance of low carbon energy and associated infrastructures: a critical discussion. Energy Policy 58, 1-5. http://dx.doi.org/10.1016/j.enpol.2013.03.018.

Bento, A.M., Li, S., Roth, K., 2010. Is There An Energy Paradox in Fuel Economy? A Note on the Role of Consumer Heterogeneity and Sorting Bias. Resources for the Future Discussion Paper.

Bubna-Litic, K., Chalifour, N.J., 2012. Are climate change policies fair to vulnerable communities? The impact of British Columbia's carbon tax and Australia's carbon pricing policy on indigenous communities. Dalhousie Law J. 35 (1), 1-52.

Cialdini, R., Demaine, L., Sagarin, B., Barrett, D., Rhoads, K., Winter, P., 2006. Managing social norms for persuasive impact. Soc. Influence 1 (1), 3-15. http:// dx.doi.org/10.1080/15534510500181459.

Consumer Federation of America, 2014. No Title. <http://www.consumerfed.org/issues/energy/motor-vehicle-fuel-efficiency> (retrieved 10.02.14). Department of Transportation, 2012. Federal Register 77 (199), 62623-63200.

Dietz, T., Dan, A., Shwom, R., 2007. Support for climate change policy: social psychological and social structural influences. Rural Sociol. $72(2), 185-214$. http://dx.doi.org/10.1526/003601107781170026.

Dillman, D., 2007. Mail and Internet Surveys: The Tailored Design Method. John Wiley Co, New York.

Dreyer, S.J., Walker, I., 2013. Acceptance and support of the Australian carbon policy. Soc. Justice Res. 26 (3), 343-362. http://dx.doi.org/10.1007/s11211-013-0191-1.

Eriksson, L., Garvill, J., Nordlund, A.M., 2008. Acceptability of single and combined transport policy measures: the importance of environmental and policy specific beliefs. Transp. Res. Part A: Policy Pract. 42 (8), 1117-1128. http://dx.doi.org/10.1016/j.tra.2008.03.006.

Gärling, T., Schuitema, G., 2007. Travel demand management targeting reduced private car use: effectiveness, public acceptability and political feasibility. J. Social Issues 63 (1), 139-153.

Greene, D.L., 1998. Why CAFE worked. Energy Policy 26 (8), 595-613. http://dx.doi.org/10.1016/S0301-4215(98)00016-0. Greene, D., 2010. How Consumers Value Fuel Economy: A Literature Review, EPA-420R-10-008.

Greene, D., Hopson, J., 2003. Analysis of alternative forms of automotive fuel economy standards for the United States. Transp. Res. Rec. 1842 (1), 20-28. http://dx.doi.org/10.3141/1842-03.

Greene, D.L., Evans, D.H., Hiestand, J., 2013. Survey evidence on the willingness of U.S. consumers to pay for automotive fuel economy. Energy Policy 61, 1539-1550. http://dx.doi.org/10.1016/j.enpol.2013.05.050.

Gross, C., 2007. Community perspectives of wind energy in Australia: the application of a justice and community fairness framework to increase social acceptance. Energy Policy 35 (5), 2727-2736. http://dx.doi.org/10.1016/j.enpol.2006.12.013.

Heath, Y., Gifford, R., 2006. Free-market ideology and environmental degradation: the case of belief in global climate change. Environ. Behav. 38 (1), 48-71.

http://dx.doi.org/10.1177/0013916505277998. 
Hefland, G., Wolverton, A., 2009. Evaluating the consumer response to fuel economy: a review of the literature. Natl. Center Environ. Econ.

Jaffe, A.B., Stavins, R.N., 1994. The energy paradox and the diffusion of conservation technology. Resour. Energy Econ. 16. http://dx.doi.org/10.1016/0928- 7655(94)900019.

Jaffe, A.B., Newell, R.G., Stavins, R.N., 2005. A tale of two market failures: technology and environmental policy. Ecol. Econ. 54, 164-174. http://dx.doi.org/ 10.1016/j.ecolecon.2004.12.027.

Kallgren, C.A., Reno, R.R., Cialdini, R.B., 2000. A focus theory of normative conduct: when norms do and do not affect behavior. Pers. Soc. Psychol. Bull. 26 (8), 1002-1012. http://dx.doi.org/10.1177/01461672002610009.

Leiserowitz, A., Maibach, E., Roser-Renouf, C., Hmielowski, J.D., 2012. Climate Change in the American Mind: Public Support for Climate and Energy Policies in March 2012.

Lewandowsky, S., Oberauer, K., Gignac, G.E., 2013. NASA faked the moon landing-therefore, (climate) science is a hoax: an anatomy of the motivated rejection of science. Psychol. Sci. 24 (5), 622-633. http://dx.doi.org/10.1177/0956797612457686.

Mahlia, T.M.I., Tohno, S., Tezuka, T., 2013. International experience on incentive program in support of fuel economy standards and labelling for motor vehicle: a comprehensive review. Renew. Sustain. Energy Rev. 25, 18-33.

http://dx.doi.org/10.1016/j.rser.2013.03.020.

McConnell, V., 2013. The New CAFE Standards: Are They Enough on Their Own? Resources for the Future Discussion Paper (May). <http://www.rff.org/ RFF/documents/RFF-DP-1314.pdf>.

National Research Council, 2002. Effectiveness and Impact of Corporate Average Fuel Economy (CAFE) Standards. Parry, I.W.H., Walls, M., Harrington, W., 2007. Automobile externalities and policies. J. Econ. Literature 45, 373-399.

Rau, I., Schweizer-Ries, P., Hildebrand, J., 2012. Participation, the silver bullet for the acceptance of renewable energies? In: Kabisch, S.K., Kunath, A.K., Schweizer-Reis, P., Steinführer, A.S. (Eds.), Vulnerability, Risks, and Complexity: Impacts of Global Change on Human Habitats. Hogrefe Publishing, pp. 177-191.

Santos, G., Behrendt, H., Maconi, L., Shirvani, T., Teytelboym, A., 2010. Part I: externalities and economic policies in road transport. Res. Transp. Econ. 28 (1), 2-45. http://dx.doi.org/10.1016/j.retrec.2009.11.002.

Schade, J., Schlag, B., 2003. Acceptability of urban transport pricing strategies. Transp. Res. Part F: Traffic Psychol. Behav. 6, 45-61. http://dx.doi.org/10.1016/ S13698478(02)00046-3.

Schuitema, G., Steg, L., Forward, S., 2010. Explaining differences in acceptability before and acceptance after the implementation of a congestion charge in Stockholm. Transp. Res. Part A: Policy Pract. 44 (2), 99-109. http://dx.doi.org/10.1016/j.tra.2009.11.005.

Skitka, L.J., Winquist, J., Hutchinson, S., 2003. Are outcome fairness and outcome favorability distinguishable psychological constructs? A meta-analytic review. Soc. Justice Res. 16 (4), 309-341.

Smith, A., 1904. In: Cannan, E. (Ed.), An Inquiry into the Nature and Causes of the Wealth of Nations, fifth ed. Metheuen and Co., Ltd, London.

Steg, L., Dreijerink, L., Abrahamse, W., 2005. Factors influencing the acceptability of energy policies: a test of VBN theory. J. Environ. Psychol. 25 (4), 415- 425. http://dx.doi.org/10.1016/j.jenvp.2005.08.003.

Steg, L., Dreijerink, L., Abrahamse, W., 2006. Why are energy policies acceptable and effective? Environ. Behav. 38 (1), 92-111. http://dx.doi.org/10.1177/ 0013916505278519.

Stern, P.C., Dietz, T., Abel, T., Guagnano, G.A., Kalof, L., 1999. A value-belief-norm theory of support for social movements: the case of environmentalism.

Human Ecol. Rev. 6 (2), 81-97.

Swim, J., Clayton, S., Doherty, T., Gifford, R., Howard, G., Reser, J., et al., 2011. Psychology and Global Climate Change: Addressing a Multifaceted Phenomenon and Set of 
Challenges.

Tabachnick, B., Fidell, L., 2013. Using Multivariate Statistics, sixth ed. Pearson.

The American Association for Public Opinion Research, 2015. Standard Definitions: Final Dispositions of Case Codes and Outcome Rates for Surveys. Thibaut, J.W., Walker, L., 1975. Procedural Justice: A Psychological Analysis. L. Erlbaum Associates, Inc., New York.

Tyler, T.R., 2000. Social justice: outcome and procedure. Int. J. Psychol. 35 (2), 117-125. http://dx.doi.org/10.1080/002075900399411. Tyler, T.R., Boeckmann, R.J., Smith, H.J., Huo, Y.J., 1997. Social Justice in Diverse Society. Westview Press, Boulder, CO.

United States Census Bureau, 2014. Quick Facts. <http://www.census.gov/quickfacts/table/PST045214/00>.

Visschers, V.H.M., Siegrist, M., 2012. Fair play in energy policy decisions: procedural fairness, outcome fairness and acceptance of the decision to rebuild nuclear power plants. Energy Policy 46, 292-300. http://dx.doi.org/10.1016/j.enpol.2012.03.062.

Wegener, D.T., Kelly, J.R., 2008. Social psychological dimensions of bioenergy development and public acceptance. Bioenergy Res. 1, 107-117. http:// dx.doi.org/10.1007/s12155008-9012-z.

Wüstenhagen, R., Wolsink, M., Bürer, M.J., 2007. Social acceptance of renewable energy innovation: an introduction to the concept. Energy Policy 35 (5), 2683-2691. http://dx.doi.org/10.1016/j.enpol.2006.12.001. 